\title{
Experimental flow studies in glaucoma drainage device development
}

\author{
The AGFID project team ${ }^{\star}$
}

\begin{abstract}
Aims-(I) To examine whether small holes produced by $248 \mathrm{~nm}$ excimer laser ablation in a polymer substrate could consistently produce a pressure drop in the desired target range $(5-15 \mathrm{~mm} \mathrm{Hg})$ at physiological aqueous flow rates for use as an internal flow restrictor in a glaucoma drainage device, and (ii) to investigate whether external leakage could be reduced in comparison with conventional tube and plate glaucoma drainage devices by redesigning the exterior cross sectional shape of the portion contained within the sclerocorneal tunnel.
\end{abstract}

Methods-Single holes with target diameters of $10 \mu \mathrm{m}, 15 \mu \mathrm{m}, 20 \mu \mathrm{m}$, and $25 \mu \mathrm{m}$ were drilled using a $248 \mathrm{~nm}$ excimer laser in sample discs $(n=6$ at each diameter) punched from a $75 \mu \mathrm{m}$ thick polyimide sheet. Sample discs were tested in a flow rig designed to measure the pressure drop across the discs. Using filtered, degassed water at a flow rate of $1.4 \mu 1 / \mathrm{min}$ repeated flow measurements were taken $(n=6)$ for each disc. After flow testing, all discs were imaged using a scanning electron microscope and the dimensions of each hole were derived using image analysis software. In the external leakage study, corneoscleral buttons $(n=13)$ were prepared from cadaver pig eyes and mounted on an artificial anterior chamber infused with Tyrode solution. After the pressure had stabilised, standard occluded silicone tube implants were inserted through 23 gauge needle stab incisions at the limbus. These were compared against prototype PMMA implants with a novel shape profile inserted through $1.15 \mathrm{~mm}$ width microvitreoretinal (MVR) stab incisions at the limbus. The infusion rate was maintained and a second pressure measurement was taken when the pressure had stabilised. The difference between the first and second pressure measurement was then compared, as an index of external leakage.

Results-Ablated tubes were found to have a near perfect circular outline on both the entry and exit side. The observed pressure drops across the ablated sample discs at each target diameter were as follows: $10 \mu \mathrm{m}$, mean 25.66 (SD 4.9) $\mathrm{mm}$ Hg; $15 \mu \mathrm{m}, 6.7$ (1.15); $20 \mu \mathrm{m}, 1.66$ (1.07); and $25 \mu \mathrm{m},<0.1 \mathrm{~mm} \mathrm{Hg}$. A strong correlation was observed between observed pressure drops and those predicted by Poiseuille's formula $\left(R^{2}=0.996\right)$. Target ablations of $15 \mu \mathrm{m}$ diameter produced tubes that consistently achieved a pressure drop within the desired range (5-15 $\mathrm{mm} \mathrm{Hg}$ ). In the external leakage study, preinsertion pressures $(\mathrm{mm} \mathbf{H g}$; mean (SD)) were 19.00 (4.3) (conventional method) and 20.00 (3.9) (new technique with PMMA prototypes). Post-insertion pressures were significantly reduced (10.40 (7.7); $p<0.01)$ for the conventional technique and were essentially unchanged for the new technique (18.80 (4.9); $p>0.1)$. Conclusions-It was shown that it is possible, in principle, to control the dimensions of a manufactured tubular lumen in a glaucoma drainage device accurately enough to provide consistent protection from hypotony in the early period after glaucoma filtration surgery. By redesigning the external profile of glaucoma drainage device and incision technique, it was also shown that it is possible to eliminate uncontrolled external leakage.

(Br F Ophthalmol 2001;85:1231-1236)

Glaucoma filtration surgery (GFS) involves the creation of a channel, or fistula, between the anterior chamber and the subconjunctival space, bypassing the compromised physiological aqueous drainage pathway through the trabecular meshwork. Many of the early postoperative complications of GFS relate to poor initial control over aqueous outflow, and safety could be considerably enhanced if resistance to flow through the drainage fistula (fistular resistance) were regulated more effectively.

Early postoperative hypotony (IOP $<5 \mathrm{~mm}$ $\mathrm{Hg}$ ) is a consistent feature of unguarded filtration procedures, including laser sclerostomy, and remains common after trabeculectomy both in the immediate postoperative period $^{1}$ and after suture release. ${ }^{2}$ Consistent control over fistular resistance in conventional GFS is difficult to achieve. The scope for human error in regulating factors such as suture tension and flap dimensions in trabeculectomy, or dissection depth in deep sclerectomy, is considerable. We are currently exploring the possibility that a 

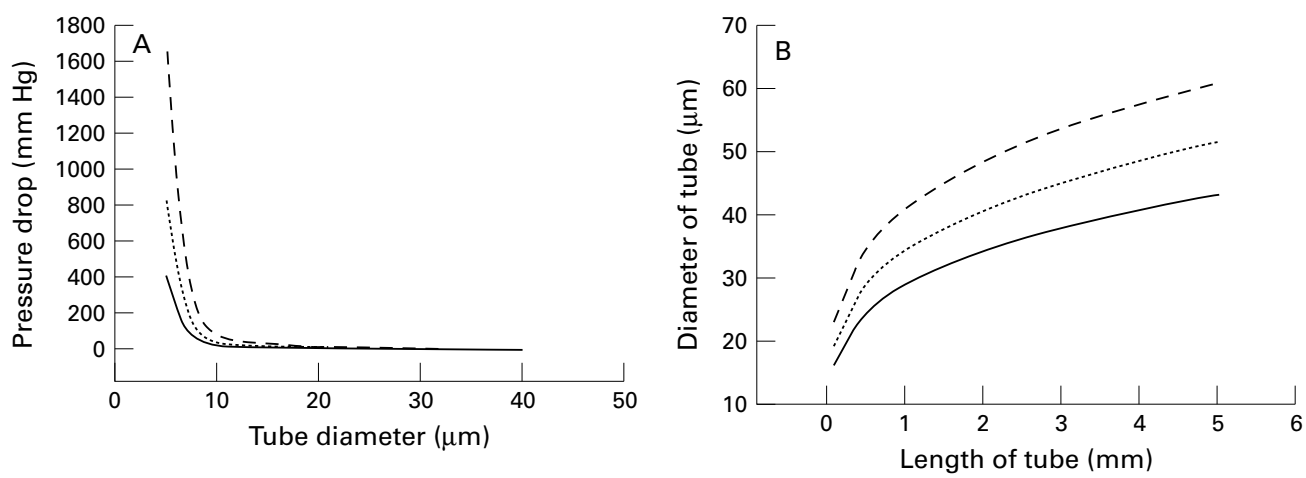

Figure 1 (A) The pressure drop across a tube versus tube diameter from Poisenille's formula 6 at a flow rate of $0.7 \mu$ l/min (solid line), $1.4 \mu \mathrm{l} / \mathrm{min}$ (dotted line), and $2.8 \mu \mathrm{l} / \mathrm{min}$ (broken line): pressure drop $=128 \mathrm{nl} \mathrm{Q} / 136 \pi d^{4}$, where $n=$ aqueous viscosity $=0.001 \mathrm{Ns} / \mathrm{m}^{2} ; l=$ length $=0.075 \mathrm{~mm}$ in this study; $Q=$ aqueous flow rate, $d=$ diameter (metres). For multiple tubes in parallel, ${ }^{6}$ the pressure drop will be given by: pressure drop $=128 n l Q / 136 \pi d^{4} N$, where $N=$ number of tubes in parallel. (B) The relation between tube diameter and length, calculated from the Poiseuille's formula, for a pressure drop across the tube of $5 \mathrm{~mm} \mathrm{Hg}$ at a flow rate of $0.7 \mu \mathrm{l} / \mathrm{min}$ (solid line), $1.4 \mu \mathrm{l} / \mathrm{min}$ (dotted line), and $2.8 \mu \mathrm{l} / \mathrm{min}$ (broken line).

Table 1 Contemporary glaucoma drainage devices: a summary of designs and materials

\begin{tabular}{lllll}
\hline GFIs & $\begin{array}{l}\text { Year of } \\
\text { introduction }\end{array}$ & Tube diameter/material & Plate size/material & $\begin{array}{l}\text { Resistance } \\
\text { mechanism }\end{array}$ \\
\hline Molteno & 1979 & $0.63 \mathrm{~mm}$ OD $0.30 \mathrm{~mm}$ ID silicone & $135 \mathrm{~mm}^{2}$ polypropylene & None \\
Baerveldt & 1990 & $0.63 \mathrm{~mm}$ OD $0.30 \mathrm{~mm}$ ID silicone & $200,250,350,425,500 \mathrm{~mm}^{2}$ silicone & None \\
Krupin with disc & 1990 & $0.58 \mathrm{~mm}$ OD $0.38 \mathrm{~mm}$ ID silicone & $180 \mathrm{~mm}^{2}$ silicone & Slit valve \\
Ahmed & 1993 & $0.63 \mathrm{~mm}$ OD $0.30 \mathrm{~mm}$ ID silicone & $185 \mathrm{~mm}^{2}$ polypropylene with silicone valve & Venturi valve \\
Optimed Model-1014 & 1995 & $0.56 \mathrm{~mm}$ OD $0.30 \mathrm{~mm}$ ID silicone & $140 \mathrm{~mm}^{2}$ silicone with PMMA matrix & Microtubules \\
\hline
\end{tabular}

$\mathrm{OD}=$ outside diameter; $\mathrm{ID}=$ inside diameter.

glaucoma drainage device (GDD) might be used to impart reproducible flow resistance in routine GFS.

Existing valved GDDs have been unsuccessful in preventing hypotony in a significant proportion of cases..$^{3-5}$ Hypotony results from poor internal flow control or uncontrolled leakage external to the device. Recent examination of pressure/flow relations in leading current devices has found that valved devices tended not to close after initial perfusion. ${ }^{5}$ Simple nonvalved flow resistors (single or multiple small diameter tubes) may therefore be preferable.

Flow resistance in a tubular channel varies with the fourth power of tube diameter in accordance with Poiseuille's formula (Fig 1A). To impart a consistent level of flow resistance, tube dimensions (the diameter in particular) must be controlled very accurately. The required level of control has never been approached by current laser sclerostomy techniques. ${ }^{7}$ Far greater accuracy should be possible for laser ablation of a homogeneous synthetic polymer substrate in controlled conditions.

In the first series of the flow experiments, we set out to examine whether small tubular holes produced by $248 \mathrm{~nm}$ excimer laser ablation in a polymer substrate could consistently impart a flow resistance in the desired target range, producing a pressure drop across specimen tubes mounted in an experimental flow rig of 5-15 $\mathrm{mm} \mathrm{Hg}$ at physiological aqueous flow rates.

Insertion of conventional GDDs into the paracentesis track produced by a standard hypodermic needle often requires considerable manipulation. Debate over the optimum needle gauge (G) continues, ${ }^{3}$ and hypotony due to external leakage remains a significant clinical problem. Redesigning the exterior of the device to facilitate introduction and improve fit should help prevent external leakage. In a further series of flow experiments, external leakage for the tube element of existing devices (Table 1) introduced conventionally was compared with a redesigned GDD and insertion technique.

\section{Materials and methods}

INTERNAL FLOW CONTROL

Single holes with target diameters of $10 \mu \mathrm{m}, 15$ $\mu \mathrm{m}, 20 \mu \mathrm{m}$, and $25 \mu \mathrm{m}$ were drilled using a 248 nm excimer laser (Fig 2) (Exitech Ltd, Oxford, $\mathrm{UK}$ ) in sample discs ( $\mathrm{n}=6$ at each diameter) punched from $75 \mu \mathrm{m}$ thick polyimide sheet (Goodfellow Ltd, Cambridge, UK). Sample discs were mounted in a flow rig (Fig 3) designed to measure the pressure drop across the discs, using filtered and degassed water as previously described, ${ }^{6}$ A flow rate of $1.4 \mu 1 / \mathrm{min}$

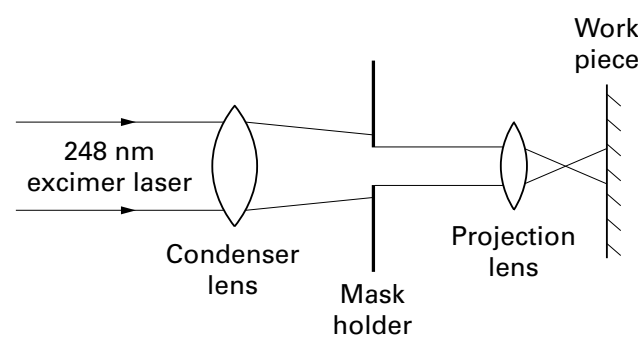

Figure 2 A schematic drawing of the $248 \mathrm{~nm}$ (krypton/fluorine) excimer laser delivery system used (Model EX-PS-2000, Exitech Ltd, Oxford, UK) (not to scale). Beam area at the target surface, and hence ablation diameter, was controlled by the mask aperture. The pulse repetition rate was set at $40 \mathrm{~Hz}$ and a total of 100 pulses were delivered to each disc. Specimens with target diameters of 10 and $15 \mu \mathrm{m}$ were ablated at a fluence of $200 \mathrm{mF} / \mathrm{cm}^{2}$ with mask diameters of 300 and $450 \mu \mathrm{m}$ respectively. Those with target diameters of 20 and $25 \mu \mathrm{m}$ were ablated at 170 $\mathrm{mF} / \mathrm{cm}^{2}$ with mask diameters of 600 and $750 \mu \mathrm{m}$. 

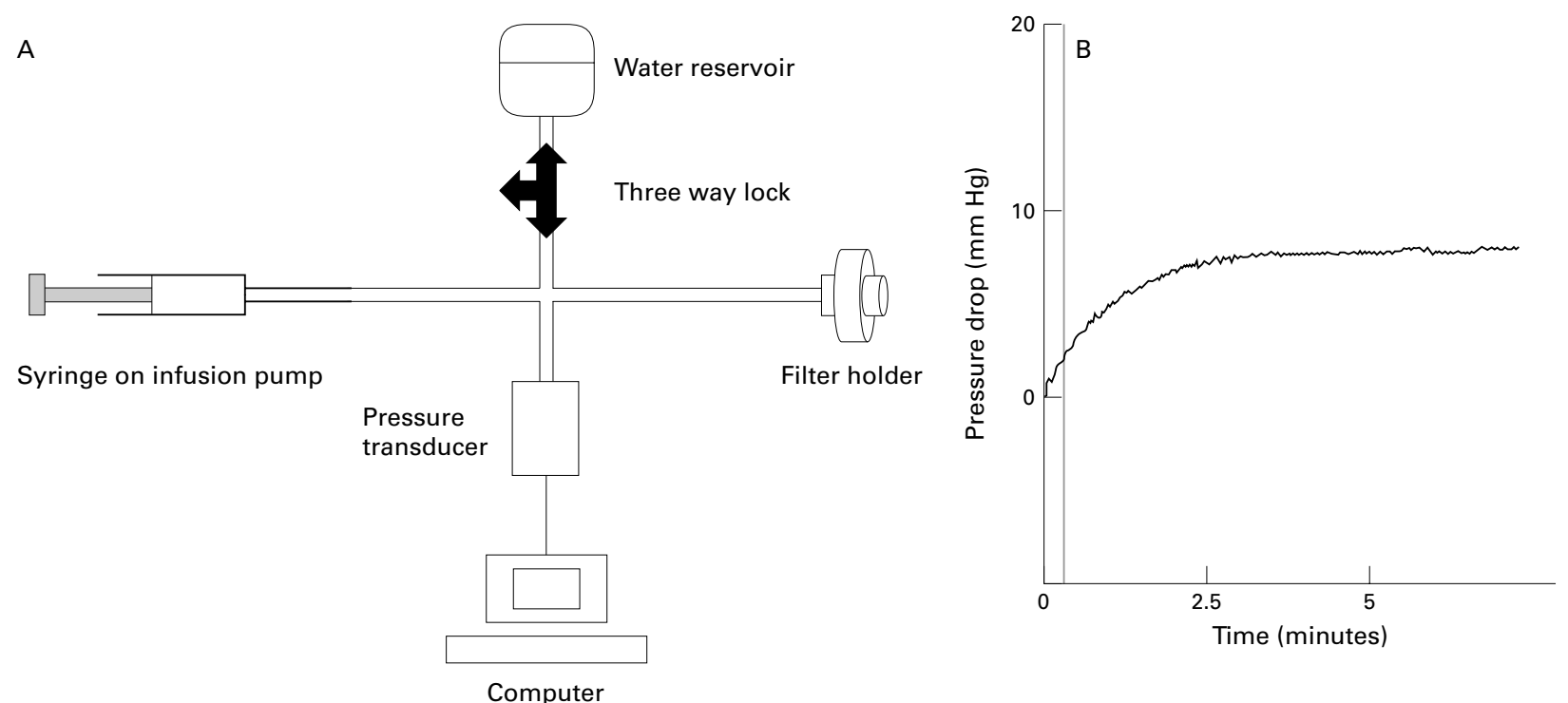

Figure 3 (A) The flow rig used was similar to that previously described for flow evaluation in GDDs. ${ }^{5}$ (B) A typical flow tracing, demonstrating stabilisation of the pressure recording within approximately 3 minutes of commencing infusion.

was used throughout. Repeated flow measurements were taken $(n=6)$ for each disc. Specimen discs were removed from their holder and remounted between each measurement.

The flow rig consisted of a pressure transducer (Model P23ID, Gould Inc, CA, USA), bridge amplifier (Model ML110, AD Instruments, New South Wales, Australia) and recorder (Model ML200, AD Instruments, New South Wales, Australia). Pressure changes were recorded using a MacLab software (v3.5 AD Instruments, New South Wales, Australia). A $1 \mathrm{ml}$ hypodermic syringe (Fortuna, Germany) was used with an adjustable electronic syringe pump (Model PHD 2000, Harvard Apparatus, MA, USA) to control the flow rate. The polyimide discs were held in a $13 \mathrm{~mm}$ stainless steel filter holder (Whatman International, Maidstone, UK). A three way lock was positioned between the water reservoir and the rest of the system. Silicone tubing (Silicone High Strength Tubing, Altec, Alton, UK) was used throughout. The transducer and the recording system were calibrated using a water manometer daily before experimentation. Once the system was filled with water, all gas bubbles were flushed out with the disc submerged in water within the filter holder. At this point, the three way lock was turned to open the system to atmospheric pressure and the pressure reading was zeroed on the computer. The three way lock was then turned to obtain a closed system and the infusion pump was started. The pressure reading was allowed to stabilise over 20 minutes and the average reading from the final 10 minutes was then taken as the pressure drop across each disc. This flow measurement was repeated six times for each disc to obtain a final averaged value.

After flow testing, all discs were coated in palladium and imaged using a scanning electron microscope (Jeol, Akishima, Japan) and the dimensions of each hole were derived using image analysis software (Scion Image, MD, USA) (Fig 4).
EXTERNAL FLOW CONTROL

Using the flow rig described earlier, in place of the filter holder, the silicone tubing was connected to an artificial anterior chamber (Fig 5) designed to mount cadaveric porcine corneoscleral buttons. The tension of the ring holder sealing the artificial anterior chamber was adjusted until no leakage was seen macroscopically.

Corneoscleral buttons $(n=13)$ were prepared from cadaver pig eyes and mounted on the artificial anterior chamber, which was infused with Tyrode solution from a microsyringe pump. As in the internal flow control study, the flow rig was connected to a pressure transducer and monitoring system. The infusion rate was adjusted to produce a target pressure in the range of $15-28 \mathrm{~mm} \mathrm{Hg}$. After the pressure had stabilised, standard occluded silicone tube implants $(0.63 \mathrm{~mm}$ external diameter) were inserted through 23 gauge needle stab incisions at the limbus (conventional technique). These were compared with prototype PMMA implants with a novel shape profile (Fig 6A) $(0.6 \mathrm{~mm} \times 1.15 \mathrm{~mm})$ inserted

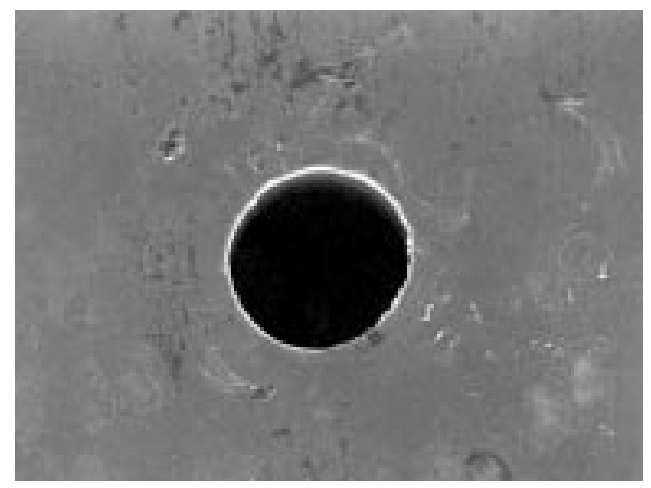

Figure 4 The inner edge of the ablated holes viewed at $90^{\circ}$ to the specimen surface by scanning electron microscopy were outlined on each side using image analysis software. The diameter a perfect circle of equivalent area was then calculated to estimate entry and exit diameters. 


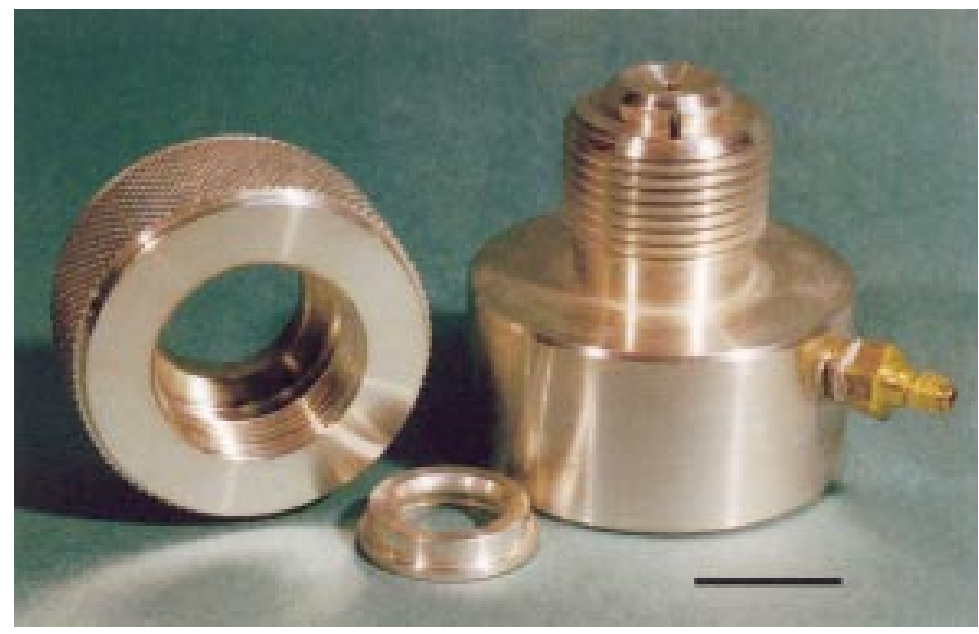

Figure 5 An artificial anterior chamber designed to mount cadaveric porcine corneoscleral buttons. through $1.15 \mathrm{~mm}$ width (20 gauge) microvitreoretinal (MVR) blade (Visitech, USA) stab incisions at the limbus (new technique) (Fig 6B). The infusion rate was maintained and a second pressure measurement was taken when the pressure had stabilised. The difference between the first and second pressure measurement was then compared, as an index of external leakage. Incisions were sutured and repeated at a different site in such a way that each implant was inserted in each eye with the order of insertion randomised.

\section{Results}

Ablated tubes were found to have a near perfect circular outline on both the entry and exit side. Observed entry and exit diameters are given in Table 2 . All holes exhibited a slight taper with entry diameters consistently larger than exit diameters.

The observed pressure drop for the specimens examined correlated very closely with that predicted by a correction of the Poiseuille's formula for tapered tubes using the observed entry and exit diameters (Fig 7A). Target ablations of $15 \mu \mathrm{m}$ diameter produced tubes that consistently achieved a pressure

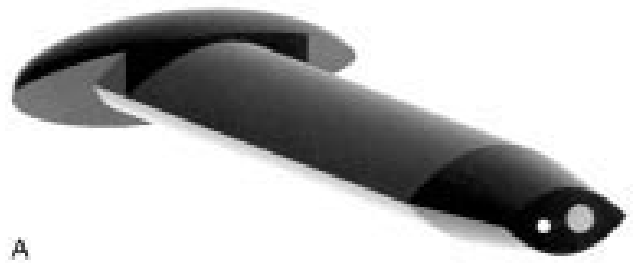

Table 2 A summary of results for the internal flow control studies. The "25 $\mathrm{\mu m}$ " holes all have $<1 \mathrm{~mm}$ Hg pressure drop

\begin{tabular}{lll}
\hline $\begin{array}{l}\text { Target hole } \\
\text { diameter }(\mu m)\end{array}$ & $\begin{array}{l}\text { Observed hole diameter } \\
(\text { mean }(S D) \mu m)\end{array}$ & $\begin{array}{l}\text { Observed pressure drop } \\
(\text { mean }(S D), \text { mmHg) }\end{array}$ \\
\hline 10 & $12.61(0.05)$ (entry side) & $25.66(4.9)$ \\
& $11(0.05)$ (exit side) & $11(0.05)$ (exit side) \\
15 & $16.67(0.82)$ (entry side) & $6.76(1.15)$ \\
& $15.1(0.25)$ (exit side) & $15.1(0.25)$ (exit side) \\
20 & $24.32(1.48)$ (entry side) & $1.66(1.07)$ \\
& $21.26(0.3)$ (exit side) & $21.26(0.3)$ (exit side) \\
25 & $28.51(3.16)$ (entry side) & $<1.0$ \\
& $27.12(0.73)$ (exit side) & \\
& & \\
& &
\end{tabular}

drop within the desired range $(5-15 \mathrm{~mm} \mathrm{Hg})$. Some variation between repeated flow measurements for the same specimen was observed (Fig 7B).

In the external leakage study, mean preinsertion pressures were 19.00 (SD 4.3) $\mathrm{mm} \mathrm{Hg}$ (conventional method) and 20.00 (3.9) $\mathrm{mm}$ $\mathrm{Hg}$ (new technique with PMMA prototypes). Post-insertion pressures were significantly reduced (10.40 (7.7) $\mathrm{mm} \mathrm{Hg}$; $<0.01$ ) for the conventional technique, and were essentially unchanged for the new techniques (18.80 (4.9) $\mathrm{mm} \mathrm{Hg} ; \mathrm{p}>0.1$ ) (Table 3 and Fig 7).

\section{Discussion}

Leading current GDDs have been developed with little available data to substantiate manufacturers' claims for flow performance ${ }^{9}$ or biocompatibility. Recent evaluation has exposed design flaws, ${ }^{10}$ poor quality control in manufacture, ${ }^{8}$ and poor flow control. ${ }^{5}$ To gain acceptance as a method of preventing hypotony in routine GFS, a new GDD must demonstrate consistent control over internal flow (flow through the GDD), good protection from external leakage (leakage between the exterior of the GDD and the sclerocorneal tissues through which it is implanted), and excellent biocompatibility. We have adapted existing methods of evaluating GDD flow performance in an examination of internal flow control using single small diameter tubes as flow resistors.

Aqueous flow in normal adult subjects during waking hours is thought to be 2.75 (SD $0.63) \mu 1 / \mathrm{min}^{11}$ but can be as low as $1.4+0.19$

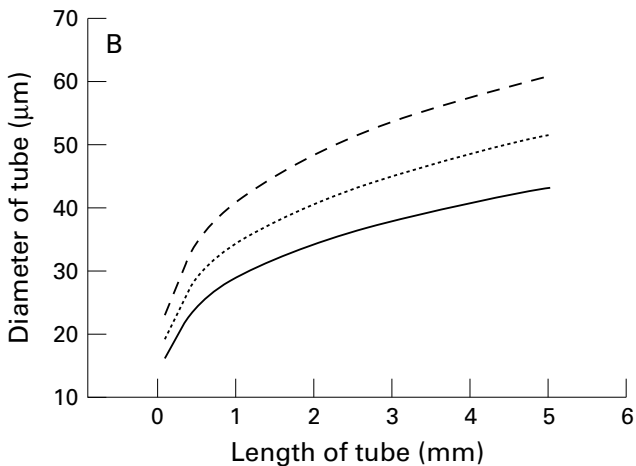

Figure 6 (A) This is one embodiment of a novel glaucoma drainage device (patent applied for) incorporating a small diameter hole (white circle) to provide the required fistular resistance and a larger diameter hole (dotted circle) temporarily occluded by a thin ablatable membrane. To give the lowest final IOP, resistance is bypassed by ablating this thin membrane using a YAG laser delivered through a gonioscope once a mature bleb is established. The external cross sectional shape of this implant is designed to bear evenly on the internal aspect of a standard microvitreoretinal (MVR) slit incision, so as to eliminate external leakage after placement. (B) A schematic drawing of the glaucoma drainage device in situ. A limbal slit incision was made parallel to the iris plane using a standard $1.19 \mathrm{~mm}$ width MVR blade to enter the anterior chamber. The occluded glaucoma drainage device was inserted through the wound, and sutured with 10/0 nylon. 

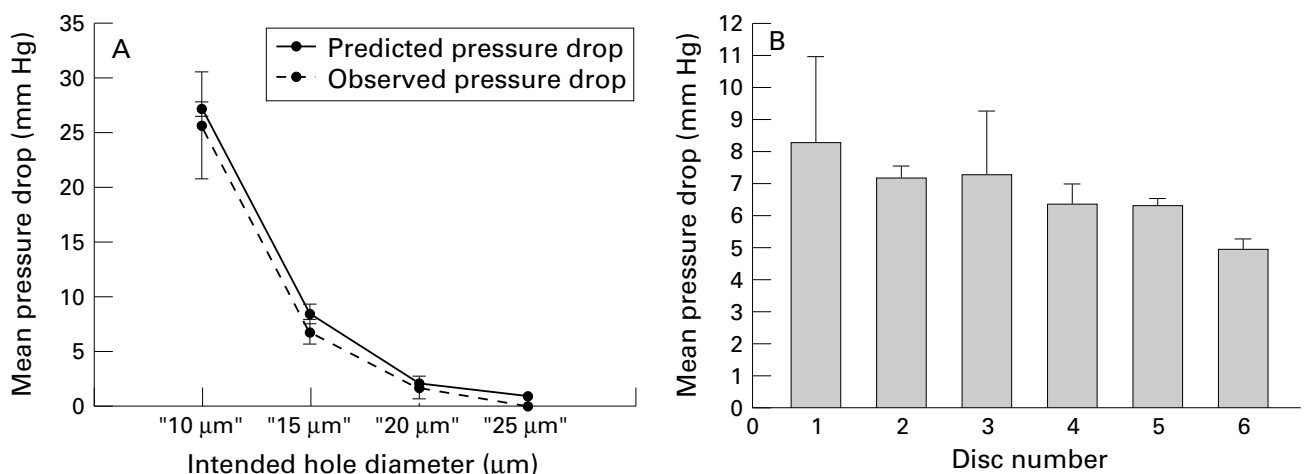

Figure 7 (A) Observed pressure drop versus predicted. Because of the tapering nature of the laser holes, the following modification of the formula was used: pressure drop $=$

$$
\frac{\mu 1 \mathrm{Q}}{17 \pi}\left[\frac{\mathrm{R}_{1}^{2}+\mathrm{R}_{1} \mathrm{R}_{2}+\mathrm{R}_{2}^{2}}{3 \mathrm{R}_{1}^{3} \mathrm{R}_{2}^{3}}\right]
$$

where $\mu=$ aqueous viscosity $=0.001 \mathrm{Ns} / \mathrm{m}^{2} ; l=$ length $=0.075 \mathrm{~mm}$ in this study; $Q=$ aqueous flow rate $=1.4 \mu \mathrm{l} / \mathrm{min}$ in this study; $R_{1}=$ radius on one side in metres, $R_{2}=$ radius on another side in metres. Note the orientation in which the disc was tested would not make any difference to the final pressure drop. (B) The pressure drop across $\approx 15 \mu \mathrm{m}$ tubes of $75 \mu \mathrm{m}$ length was consistently within the desired target range $(5-15 \mathrm{~mm} \mathrm{Hg})$ at a flow rate of $1.4 \mu \mathrm{l} / \mathrm{min}$. Some variation between specimens attributable to dimensional variation was observed along with some variation between measurements $(n=6)$ for the same specimen.

$\mu \mathrm{l} / \mathrm{min}$ during sleep. ${ }^{12}$ Since the main aim in our experimentation was to examine protection from hypotony, the rate of fluid flow was set $(1.4 \mu \mathrm{l} / \mathrm{min})$ at the lower end of anticipated physiological levels.

The good fit between the observed pressure drop across specimen tubes and that predicted by the Poiseuille formula was an expected finding. Poiseuille's formula is applicable where laminar flow exists in a fluid of uniform viscosity contained within a rigid tube. Uniform viscosity can be assumed for aqueous, and the likelihood of turbulence within a system increases with flow velocity. Physiological flow rates are sufficiently slow that laminar flow would be established within $2 \mu \mathrm{m}$ of tube entrance, and edge effects would be insignificant. Low level lumenal elasticity would be tolerated in any GDD system using small diameter tubes as flow restrictors.

Polyimide is widely available, inexpensive, and absorbs light strongly at $248 \mathrm{~nm}$. Relatively thin sheets $(75 \mu \mathrm{m})$ were used to facilitate accurate ablation, and to allow for the possibility of subsequent perforation using an Nd:YAG laser to abolish fistular resistance. The fistular resistance would only normally be required in the early postoperative period, before the development of a mature conjunctival filtration bleb and adequate resistance to flow distal to the GDD. A $<20 \mu \mathrm{m}$ hole could block even with a single macrophage and is unlikely to be practical as a flow resistor in vivo. Longer tubes imparting equivalent fistular resistance would allow the use of larger diameters (Fig 1B), and could be incorporated alongside a larger diameter, low resistance tube guarded by a thin YAG ablatable membrane in a GDD with reversible fistular resistance (Fig 6).

Table 3 A summary of results for the external flow control studies

\begin{tabular}{ll}
\hline Paracentesis & $\begin{array}{l}\text { Mean pressure (SD) } \\
\text { ( } m m \text { Hg) }\end{array}$ \\
\hline Pre MVR & $19.00(4.3)$ \\
Post PMMA prototypes & $10.40(7.7)$ \\
Pre 23 gauge & $20.00(3.9)$ \\
Post silicone tubes & $18.80(4.9)$ \\
\hline
\end{tabular}

The observed variation between flow measurements for given specimens (Fig 7B) may have been attributable to minor accretions of debris within the tube lumens during specimen handling. This highlights the importance of using a material that would resist protein conditioning and cellular adhesion in vivo. We have recently examined the use of phosphorylcholine based polymers in this context, and found that resistance to protein and cellular spoilation is greatly reduced in comparison materials used in conventional GDDs. ${ }^{13}$

The excimer laser system used was nondedicated. Improvements in laser delivery are possible that would enhance accuracy and reduce the taper produced by a convergent beam. Extrusion and moulding technologies may also be applicable, particularly where longer tubes are used. Even with the system used, ablation was considerably more accurate than for laser sclerostomy. ${ }^{7}$

Consistent internal flow control is of little value if a good seal around the device does not exist. Conventional GDDs have a standard silicone tube element, which is introduced through a paracentesis created with either a 22 gauge or 23 gauge needle. ${ }^{3}$ Considerable manipulative force is required for introduction, and this may result in tissue tearing and enlargement of the paracentesis tract. The tapered leading edge of our redesigned device allowed insertion with minimal force. This study has shown that even 23 gauge paracentesis tracts were liable to cause significant leakage in some eyes and that improving the fit between the external profile of a new GDD and the incision through which it is inserted should minimise uncontrolled external leakage.

We have shown that it is possible in principle to control the dimensions of a manufactured tubular lumen in a GDD accurately enough to provide consistent protection from hypotony in the early period after GFS, and demonstrated that consistent protection from external leakage can be obtained with appropriate design modifications. Using appropriate bioinert materials, it should be possible to develop a GDD 
suitable for routine use in GFS, which would both simplify the procedure and enhance the consistency of early postoperative pressure control.

The AGFID project team members

K S Lim, ${ }^{12}$ B Allan, ${ }^{3}$ P T Khaw, ${ }^{13} \mathrm{~S}$ Willis, ${ }^{4} \mathrm{~A}$ W Lloyd,${ }^{2}$ A Muir, ${ }^{4}$ P Gard,${ }^{2}$ R G A Faragher, ${ }^{2}$ C J Olliff, ${ }^{2}$ G W Hanlon, ${ }^{2}$ L Wong, ${ }^{2} S$ Reed, ${ }^{2}$ and S Denyer. ${ }^{2}$

1 Institute of Ophthalmology, London, UK; 2 University of Brighton, Brighton, UK; 3 Moorfields Eye Hospital, London, UK; 4 Biocompatibles Ltd, Farnham, UK.

Supported by the Department of Trade and Industry/ Department of Health's Medical Implant LINK programme, UK and International Glaucoma Association.

$\mathrm{K}$ and International Glaucoma Association. Research in Vision and Ophthalmology, May 1998, Fort Research in Vision and

The Institute of Ophthalmology, University of Brighton, and The Institute of Ophthalmology, University of Brighton, and
Moorfields Eye Hospital have the proprietary interest in the glaucoma drainage device being developed.

1 Fluorouracil Filtering Surgery Study Group. One year follow-up. Am f Ophthalmol 1989;108:625-35.
2 Block et al. Invest Ophthalmol Vis Sci 1992;33:2898.

3 Coleman AL, Hill R, Wilson MR, et al. Initial clinical experience with the Ahmed glaucoma valve implant. Am $\mathcal{F}$ Ophthalmol 1995;120:23-31.

4 Krupin Eye Valve Filtering Surgery Study Group. Krupin eye valve with disk for filtration surgery. Ophthalmology 1994;101:651-8

5 Prata JA, Mermoud A, LaBree L, et al. In vitro and in vivo flow characteristics of glaucoma drainage implants. Ophthalmology 1995;102:894-904

6 McEwen WK. Application of Poiseuille's law to aqueous outflow. Arch Ophthalmol 1958;60:290-4.

7 Allan BDS, van Saarloos PP, Vijayasekaran S, et al. Excimer laser sclerostomy: tissue damage and dimensional reproducibility in vitro. Lasers Light Ophthalmol 1993;5:121-30.

8 Porter JM, Krawczyk CH, Carey RF. In vitro flow testing of glaucoma drainage devices. Ophthalmology 1997;104:1701-

9 Krawczyk CH. Glaucoma drainage devices and the FDA. Ophthalmology 1995;102:1581-2.

10 Lee VW. Glaucoma Avalves' B truth versus myth [letter]. Ophthalmology 1998;105:567-8.

11 Brubaker RF. Flow of aqueous-humor in humans. The Friedenwald Lecture. Invest Ophthalmol Vis Sci 1991;32: 3145-66.

12 Reiss GR, Lee DA, Topper JE, et al. Aqueous humor flow during sleep. Invest Ophthalmol Vis Sci 1984;25:776.

$13 \mathrm{Lim}$ KS, Faragher RGA, Reed S, et al. Cell and protein adhesion studies in glaucoma drainage device development. Br f Ophthalmol 1999;83:1168-72.

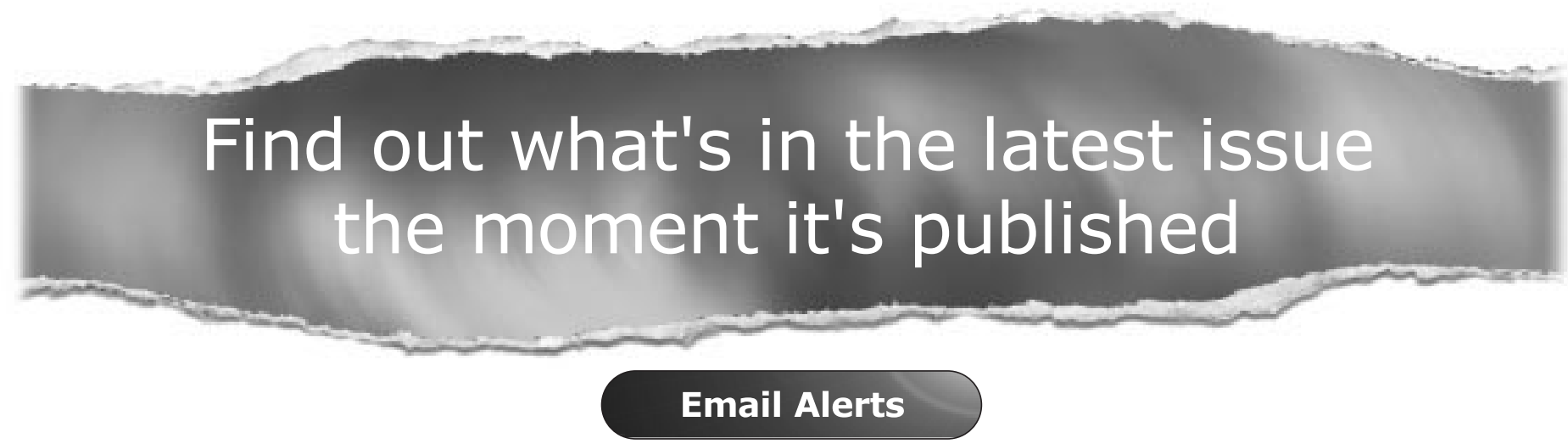

Sign up to receive the table of contents by email every month. You can select from three alerts: Table of Contents (full), TOC Awareness (notice only); British Journal of Ophthalmology related announcements.

www.bjophthalmol.com 